\title{
Appropriateness of Referral for Upper Gastrointestinal Endoscopy in a Tertiary Care Hospital \\ Khan $\mathrm{MMR}^{1}$, Wahab $\mathrm{MA}^{2}$, Yasin $\mathrm{MM}^{3}$, Zafreen $\mathrm{F}^{4}$ \\ DOI: https://doi.org/10.3329/jafmc.v14i2.45897
}

\begin{abstract}
Introduction: Upper gastrointestinal endoscopy (UGE) allows physicians to directly schedule endoscopic procedures for their patients without prior consultation. Evaluation of appropriateness of endoscopic procedures is associated with costs and benefits.
\end{abstract}

Objectives: To assess the appropriateness of the use of UGE in an open-access setting in Bangladesh.

Materials and Methods: This cross-sectional multicenter study was conducted among 300 patients referred for UGE at Dhaka Medical College Hospital and Shaheed Suhrawardi Medical College and Hospital from January 2016 to June 2016. The American Society for Gastrointestinal Endoscopy (ASGE) guidelines was used to assess the appropriateness of referral. The participants were selected by purposive nonprobability sampling and a pre-tested questionnaire was used for data collection.

Results: Out of 300 respondents $62.3 \%$ was male. History of smoking was more in male and taking NSAIDs were more in the female. In UGE $46.7 \%$ revealed normal findings but majority $53.3 \%$. had some pathology. About $86 \%$ cases, UGE was found appropriate according to ASGE guideline and majority appropriate cases $37.3 \%$ were referred by internal medicine specialist. Appropriateness of referral among different physicians was not statistically significant.

Conclusion: Appropriateness of referral for UGE performed in tertiary care level hospitals in an open-access setting like Bangladesh was satisfactory.

Key-words: Upper gastrointestinal endoscopy, Peptic ulcer diseases.

\section{Introduction}

Upper gastrointestinal endoscopy (UGE) is one of the most commonly performed medical procedures globally. Progress in endoscopic technology has advanced the practice of medicine as it relates to the gastrointestinal tract. Over the last thirty years, scientists and clinicians have acquired unprecedented access to the gastrointestinal lumen, the pancreatic and biliary ductal system. Open-access endoscopy allows physicians to directly schedule endoscopic procedures for their patients without prior consultation. Esophagogastroduodenoscopy (EGD) affords an excellent view of mucosal surfaces of the oesophagus, stomach and proximal duodenum. Direct examination of the mucosal surface provides greater information than that gained by two-dimensional scans and x-rays ${ }^{1}$.

It is estimated that $1 \%$ of the population of the United Kingdom require EGD every year ${ }^{2}$. Approximately 70,000 outpatient UGE is performed each year in Switzerland which has a population of 7.2 million $^{3}$. The diseases most commonly sought out by endoscopy are reflux oesophagitis, oesophageal varices, oesophageal cancer, gastric ulcer, gastric cancer, duodenal ulcer and coeliac disease. Most patients referred for endoscopy complaining of symptoms that come under the general heading of dyspepsia. Gastrointestinal symptoms are responsible for about $10 \%$ work of general practitioners with upper abdominal symptoms accounting for about half of the complaints ${ }^{4,5}$.

\section{Materials and Methods}

This Cross-sectional multicenter study was conducted among 300 patients who were referred to Dhaka Medical College Hospital and Shaheed Suhrawardi Medical College and Hospital for open-access EGD during the period of 6 months from January 2016 to June 2016. The American Society for Gastrointestinal Endoscopy (ASGE) guideline was used to assess appropriateness for referral ${ }^{5}$. Purposive type of non-probability sampling technique was applied to enrol the study participants. Data were collected by using a pre-tested questionnaire and neither any intervention nor any invasive procedure was undertaken. Before starting interview, a brief introduction on the aims of the study was presented to the respondents and informed written consent was taken. The collected data were thoroughly checked for consistency and completeness. Data were coded and analyzed using Statistical Package for Social Sciences (SPSS) version 23. Chi-square test was performed to find the association between variables and $p$-value $<0.05$ considered as significant.

1. Group Captain Md Mizanur Rahman Khan, MBBS, MPH, MPhil, Officer in Charge \& Senior Medical Officer, Medical Squadron, Bangladesh Air Force Base Bashar (E-mail: mizanurrahmankhan@gmail.com) 2. Lt Col Md Abdul Wahab, MBBS, MD, Associate Professor of Biochemistry, AFMC, Dhaka 3. Wing Commander Md Muaz Yasin, Graded Specialist in Medicine, Medical Squadron, Bangladesh Air Force Base Bashar 4. Dr Farzana Zafreen, MBBS, MPH, Associate Professor and Head, Department of Community Medicine, Medical College for Women \& Hospital, Uttara, Dhaka. 


\section{Results}

In the present study among 300 subjects, $62.3 \%$ were male with a male to female ratio $1.7: 1$. About $62 \%$ of respondents were below this age group 46 years and $80 \%$ had monthly family income below 10,000 taka whereas only $4.3 \%$ had income over 20,000 taka. The literacy rate among the respondents showed $32.7 \%$ were illiterate and only $11.7 \%$ were graduate and above (Table-I). Among the male respondents $70.6 \%$ had history of smoking and $32.7 \%$ female had history of taking long term NSAIDs. About $86 \%$ indications were appropriate according to ASGE guideline (Table-II). About appropriateness of referral for UGE by different physicians was not statistically significant $p$-value $>0.05$ (Table-III). According to UGE findings $46.7 \%$ found normal, $12.7 \%$ had PUD, $3 \%$ gastric ulcer, $7 \%$ gastritis, $5.3 \%$ gastric tumor, $14.7 \%$ esophageal varices, $5 \%$ had reflux esophagitis, 2.3\% Esophageal carcinoma and 3\% others (Table-IV).

Table-I: Socio-demographic characteristics of the respondents $(n=300)$

\begin{tabular}{|l|l|c|c|}
\hline \multicolumn{2}{|c|}{ Characteristics } & Frequency & Percentage \\
\hline \multirow{3}{*}{ Age in Years } & 15 to 45 & 186 & 62 \\
\cline { 2 - 4 } & 46 to 95 & 114 & 38 \\
\hline \multirow{4}{*}{ Sex } & Male & 187 & 62.3 \\
\cline { 2 - 4 } & Female & 113 & 37.7 \\
\hline \multirow{5}{*}{ Education Status } & llliterate & 98 & 32.7 \\
\cline { 2 - 4 } & Up to primary & 41 & 13.7 \\
\cline { 2 - 4 } & Up to SSC & 80 & 26.7 \\
\cline { 2 - 4 } & Up to HSC & 43 & 14.3 \\
\cline { 2 - 4 } & Graduate and above & 35 & 11.7 \\
\cline { 2 - 4 } Income in Taka & Others & 03 & 01 \\
\hline \multirow{2}{*}{ Monthly Family } & $<10,000$ & 240 & 80 \\
\cline { 2 - 4 } & 10,000 to 20,000 & 47 & 15.7 \\
\cline { 2 - 4 } & $>20000$ & 13 & 4.3 \\
\hline
\end{tabular}

Table-II: Distribution of Respondents according to referring indications $(n=300)$

\begin{tabular}{|c|c|c|}
\hline \multicolumn{2}{|r|}{ Indications } & $\begin{array}{l}\text { Frequency } \\
(\%)\end{array}$ \\
\hline \multirow{4}{*}{$\begin{array}{l}\text { Appropriate } \\
\text { Indications }\end{array}$} & $\begin{array}{l}\text { Upper abdominal symptoms persistent } \\
\text { despite therapy }\end{array}$ & $96(32)$ \\
\hline & $\begin{array}{l}\text { Upper abdominal symptoms associated } \\
\text { with symptoms or signs suggesting serious } \\
\text { organic disease }\end{array}$ & $17(5.7)$ \\
\hline & $\begin{array}{l}\text { Upper abdominal symptoms associated with } \\
\text { symptoms or signs in patients aged }>45 \text { yrs }\end{array}$ & $13(4.3)$ \\
\hline & Dysphagia or odynophagia & $16(5.3)$ \\
\hline & $\begin{array}{l}\text { Oesophagal reflux symptoms persistent or } \\
\text { recurrent despite therapy }\end{array}$ & 03(01) \\
\hline & Persistent vomiting of unknown cause & 12(04) \\
\hline & Active or recent Gl bleeding & $41(13.7)$ \\
\hline & $\begin{array}{l}\text { Presumed chronic blood loss/iron deficiency } \\
\text { anaemia }\end{array}$ & $02(0.7)$ \\
\hline & Sampling of tissue or fluid & $02(0.7)$ \\
\hline & To document or treat oesophagal varices & $49(16.3)$ \\
\hline & Other appropriate indications & $06(1.9)$ \\
\hline & Total & $258(86)$ \\
\hline
\end{tabular}

\begin{tabular}{|c|c|c|}
\hline \multicolumn{2}{|r|}{ Indications } & $\begin{array}{l}\text { Frequency } \\
(\%)\end{array}$ \\
\hline \multirow{8}{*}{$\begin{array}{l}\text { Inappropriate } \\
\text { Indications }\end{array}$} & Healing of duodenal ulcer & $09(3)$ \\
\hline & $\begin{array}{l}\text { Surveillance of healed benign disease such } \\
\text { as esophagitis or gastric or duodenal ulcer }\end{array}$ & $03(1)$ \\
\hline & Functional in origin & $09(3)$ \\
\hline & $\begin{array}{l}\text { Uncomplicated heartburn responding to } \\
\text { medical therapy }\end{array}$ & $15(5)$ \\
\hline & $\begin{array}{l}\text { Metastatic adenocarcinoma of unknown } \\
\text { primary site }\end{array}$ & $04(1.3)$ \\
\hline & $\begin{array}{llll}\text { elective surgery } & \text { for } & \text { non-upper } \\
\text { gastrointestinal disease } & & \\
\end{array}$ & $01(0.3)$ \\
\hline & To confirm radiologic lesions & $01(0.3)$ \\
\hline & Total & $42(14)$ \\
\hline
\end{tabular}

Table III: Cross Tabulation between referring physicians and appropriateness of indication $(n=300)$

\begin{tabular}{|c|c|c|c|c|}
\hline \multirow{2}{*}{$\begin{array}{l}\text { Referring } \\
\text { Physicians }\end{array}$} & \multicolumn{3}{|c|}{ Appropriateness of Referring Indication } & \multirow{2}{*}{ Statistics } \\
\hline & Appropriate & Inappropriate & Total & \\
\hline Gastroenterologist & 39 & & & \multirow{5}{*}{$\begin{array}{l}\chi^{2}=2.64 \\
d f=3 \\
p>0.05\end{array}$} \\
\hline $\begin{array}{l}\text { Internal medicine } \\
\text { specialist }\end{array}$ & 112 & 14 & 12 & \\
\hline General Physician & $86(28.7 \%)$ & & $102(34)$ & \\
\hline Others & $21(7)$ & $6(2 \%)$ & $27(9)$ & \\
\hline Total & $258(86)$ & $42(14)$ & $300(100)$ & \\
\hline
\end{tabular}

Table-IV: Distribution of respondents by endoscopic findings $(n=300)$

\begin{tabular}{|l|c|}
\hline Endoscopic Findings & Frequency (\%) \\
\hline Normal & $140(46.7)$ \\
\hline PUD & $38(12.7)$ \\
\hline Gastric ulcer & $09(03)$ \\
\hline Gastritis & $21(07)$ \\
\hline Gastric tumour & $16(5.3)$ \\
\hline Pyloric stenosis & $01(0.3)$ \\
\hline Oesophagal varices & $44(14.7)$ \\
\hline Reflux esophagitis & $15(05)$ \\
\hline Oesophagal carcinoma & $07(2.3)$ \\
\hline Miscellaneous & $09(03)$ \\
\hline
\end{tabular}

\section{Discussion}

In Bangladesh, the exact aetiological and clinical presentation of gastrointestinal diseases are not researched in vast. To find out appropriate referring indications the cross-sectional study was carried out enrolling 300 subjects aged between 15-95 years in Dhaka Medical College Hospital and Shaheed Suhrawardy Medical College Hospital, Dhaka.

In this present study, $62.3 \%$ were male with a male: female ratio of 1.7:1. Age ranging from 15 to 95 years with a median age of 40 years, $38 \%$ of respondents were above the age group $\geq 46$ years. Most of the respondents $55 \%$ were in the age group of 26 to 50 years, $26.7 \%$ were above 50 years and the rest $18.3 \%$ were below 25 years (Table-I). This reflects that during the active age of life these upper GI symptoms occur most. In a study in India, the findings are similar that mean age of patients who went for endoscopy was $41.7 \pm 12.7$ years, and among them $34 \%$ were female ${ }^{6}$. These findings are more or less similar to another study carried out at Rajshahi Medical College Hospital in which average age of the patients was 39.9 
years with the range of $18-90$ years. $50 \%$ of patients were in the age range of 20-39 years ${ }^{7}$. In Ghana ages ranged from $14-95$ years with a mean of $46.01 \pm 16.97$ years ${ }^{8}$. But this result does not correlate with western countries ${ }^{9,10,11}$, where mean age of their patients was over 50 years of age. Epidemiology of dyspeptic symptoms in Asian region differs from that in the West. It might be due to improved hygiene and ability to buy potent anti-secretory and ulcerogenic drugs.

Among the respondents, $80 \%$ had monthly income below 10,000 whereas, only $4.3 \%$ had income over 20,000 . Monthly income mean $( \pm S D)$ was $8748.7( \pm 6301.27)$ Taka (Table-I). These findings are also more or less similar to another Bangladeshi data carried out five years back, where most of the patients were from a low socio-economic condition with a mean $( \pm S D)$ monthly income of taka $4080( \pm 2045)^{7}$. Among total patients, $46.4 \%$ were Illiterate and had primary education, $41 \%$ had higher secondary education and $12 \%$ had graduation and above (Table-I). This result is also similar to an Asian study where, none/primary were $44.9 \%$, secondary $42.2 \%$, and tertiary $12.8 \%^{12}$.

Among the participants, $46 \%$ had history of smoking in which $5.3 \%$ was female. Moreover, $22.3 \%$ had history of taking long term NSAIDs and $32.7 \%$ among them were females (Table-II). Smoking history is not similar but history of taking NSAIDs was more or less similar to another Asian study where 855 had no history of taking NSAIDs ${ }^{13}$.

Of the 300 referrals, $86 \%$ were classified as appropriate according to ASGE guidelines, and $14 \%$ as inappropriate (Table-III). Among all referring physician 15\% were Gastroenterologist, $34 \%$ general practitioners, $42 \%$ internal medicine specialist and $9 \%$ others. Of all inappropriate indications General practitioners were most 5.3\%, Internal medicine specialist $4.7 \%$ gastroenterologist $2 \%$ and this would suggest caution in opening access to endoscopy to non-specialists (Table-IV). In a study in Ghana in case of referring physician $15 \%$ were gastroenterologist and rest were others ${ }^{8}$. Appropriateness is more or less similar to another Asian study in Malaysia where appropriate rate was $88.35 \%$ and inappropriate rate was $11.7 \%{ }^{8}$, in Israel where appropriateness rate was $84.1 \%$ and inappropriate rate was $15.9 \%^{12}$ and USA study where appropriate rate was $84 \%^{14}$. But referring physician category is not the same with other studies ${ }^{13}$.

The most common appropriate indications were upper abdominal symptoms persistent despite an appropriate trial of therapy $32 \%$ (Table-III). This also was the most frequent appropriate indication in another Asian study ${ }^{12}$ and another study in Italy ${ }^{15}$. On the other hand, the most frequent inappropriate indications were uncomplicated heartburn responding to medical therapy $5 \%$, healing of duodenal ulcer and functional in origin both $3 \%$, metastatic adenocarcinoma of unknown primary site $1.3 \%$ (Table-III). In many other European and American studies indications are not the same. That might be in developing countries like Bangladesh due to lack of proper nutrition, hygiene and unhealthy lifestyle.

Among findings $12.7 \%$ had PUD, 3\% gastric ulcer, $7 \%$ gastritis, $5.3 \%$ gastric tumor, $14.7 \%$ oesophageal varices, $5 \%$ reflux oesophagitis, $2.3 \%$ oesophageal carcinoma and $3 \%$ others (Table-V). This study finding is more or less similar with other findings revealed by endoscopy in Bangladesh ${ }^{16}$ where gastroduodenal mucosa was found normal in $58.14 \%$, gastritis in $11.63 \%$, duodenitis $2.33 \%$, reflux oesophagitis $4.65 \%$, peptic ulcer $17.44 \%$ and carcinoma of stomach $5.81 \%$. In another study in Bangladesh, endoscopy revealed that duodenal ulcer $34 \%$ was the most common cause of UGI bleeding followed by rupture of portal varices $16 \%$, neoplasm $10 \%$, gastric ulcer $08 \%$ and gastric erosion $06 \%{ }^{8}$. A normal endoscopic examination is not considered significant, although this may be relevant to patient care in helping to rule out a serious pathologic condition. A negative endoscopy in dyspeptic patients significantly reduce the number of specialist consultation and lessens the burden on the medical system. Other studies ${ }^{17,18}$ have demonstrated better quality of life and patient satisfaction with normal endoscopy.

\section{Conclusion}

This study revealed that the appropriateness of referral for upper $\mathrm{Gl}$ endoscopy performed in tertiary care level hospitals in an open-access setting like Bangladesh is more or less satisfactory. A further improvement of the effectiveness of endoscopy can be achieved by creating awareness among physicians and preparing a national guideline in this aspect.

\section{References}

1. Appropriate use of Gastrointestinal Endoscopy. Gastrointestinal Endoscopy 2000; 62(6):3-4

2. British Society of Gastroenterology. Provision of gastrointestinal endoscopy and related services for a district general hospital. London: BSG 1990; 61(3):5-6

3. Adang R, Vismans JF, Talmon JL et al. The diagnostic outcome of upper gastrointestinal endoscopy: are referral source and patient age determining factors? European journal of gastroenterology \& hepatology 1994; 6:329-35.

4. Axon AT, Bell GD, Jones RH et al. Guidelines on appropriate indications for upper gastrointestinal endoscopy. BMJ 1995; 310(6983):853-6.

5. American society for gastrointestinal endoscopy (ASGE) developed guideline 1988 .

6. DuttaAK, Chacko A, Balekuduru Aet al. Time trends in epidemiology of peptic ulcer disease in India over two decades. Indian Journal of Gastroenterology 2012; 31(3):111-5. 
7. Ahmed MU, Ahad MA, Alim MA et al. Etiology of upper gastrointestinal haemorrhage in a teaching hospital. TAJ: Journal of Teachers Association 2008; 21(1):53-7.

8. Tachi K, Nkrumah KN. Appropriateness and diagnostic yield of referrals for Oesophagogastroduodenoscopy at the Korle Bu Teaching Hospital. West African Journal of Medicine 2011; 30(3):158-63.

9. Quine MA, Bell GD, McCloy RF et al. Prospective audit of upper gastrointestinal endoscopy in two regions of England: safety, staffing, and sedation methods. Gut 1995; 36(3):462-7.

10. Minoli G, Prada A, Gambeta G et al. The ASGE guidelines for the appropriate use of upper gastrointestinal endoscopy in an open access system. Gastrointestinal Endoscopy 1995; 42:387-9.

11. Trevisani L, Sartori S, Gilli G et al. Appropriateness of upper gastrointestinal endoscopy: A hospital-based study. Dig Dis Sci 2001; 46:2695-9

12. Keren D, Rainis T, Stermer E et al. A nine-year audit of openaccess upper gastrointestinal endoscopic procedures: Results and experience of a single centre. Canadian Journal of Gastroenterology and Hepatology 2011; 25(2):83-8.
13. Chan YM, Goh KL. Appropriateness and diagnostic yield of EGD: A prospective study in a large Asian hospital. Gastrointestinal Endoscopy 2004; 59:51

14. Zuccaro G, Provencher K. Does an open access system properly utilize endoscopic resources? Gastrointestinal Endoscopy 1997; 46:15-20.

15. Hassan C, Bersani $G$, Buri $L$ et al. Appropriateness of upper-GI endoscopy: An Italian survey on behalf of the Italian Society of Digestive Endoscopy. Gastrointestinal Endoscopy 2007; 65(6):767-74.

16. Islam MD, Rahman SH, Shamsuzzaman SM et al. Comments on Evaluation of Endoscopic Findings and Detection of $\mathrm{H}$. pylori Antibody by Serum IgG ELISA. Faridpur Medical College Journal 2011; 6(1):24-7.

17. Wiklund I, Glise H, Jerndal P et al. Does endoscopy have a positive impact on quality of life in dyspepsia? Gastrointestinal Endoscopy 1998; 47(6):449-54.

18. Rabeneck L, Wristers K, Souchek J et al. Impact of upper endoscopy on satisfaction in patients with previously uninvestigated dyspepsia. Gastrointestinal Endoscopy 2003; 57(3):295-9. 